\title{
SOBRE OS PAPÉIS DO HOMEM E DA MULHER NO CONCEITO DE FAMÍLIA DA FILOSOFIA DO DIREITO DE HEGEL
}

\author{
Marloren Lopes Miranda ${ }^{1}$ \\ Universidade Federal do Rio Grande do Sul (UFRGS) \\ (D) https://orcid.org/0000-0001-6875-9580
}

\begin{abstract}
RESUMO:
Na Filosofia do Direito, a família é a instituição mais imediata da eticidade, do sistema de costumes de uma época que efetiva o conceito de liberdade dentro de seus limites espaço-temporais. Nesse sentido, a família é o momento no qual seus membros estão mais ligados à natureza, embora já estejam no âmbito do espírito. Por isso, Hegel determina, no seu conceito de família, papéis para seus membros de acordo com seus respectivos sexos, em uma tentativa de suprassumir a natureza no espírito, sem negá-la. Esse trabalho visa a questionar se as atribuições dos papéis espirituais de acordo com o sexo natural dos membros da família que Hegel faz são coerentes com de teses e conceitos mais fundamentais de seu próprio sistema, como a relação entre as noções de natureza e espírito, e questionar se, assim, sua filosofia pode cumprir com o seu propósito mais fundamental, o de efetivar a ideia de liberdade na instância familiar.
\end{abstract}

PALAVRAS-CHAVE: Família; Gênero; Natureza; Espírito; Razão.

\section{ON THE ROLES OF MEN AND WOMEN IN THE CONCEPT OF FAMILY OF HEGEL'S PHILOSOPHY OF RIGHT}

\begin{abstract}
:
In Hegel's Philosophy of Right, family is the most immediate institution of the ethical life, i.e., the system of customs that realize the concept of freedom within the spatiotemporal limits of a determined epoch. In this sense, family is the moment wherein its members are more involved in nature, although they already live in the domain of spirit. As a consequence, Hegel determines the roles for the members of family according to the respective genders, in the attempt to sublate nature into spirit without

\footnotetext{
${ }^{1}$ Doutoranda em Filosofia pela Universidade Federal do Rio Grande do Sul (UFRGS), Rio Grande do sul - Brasil. Bolsista CAPES. E-mail: marloren.miranda@ hotmail.com
} 
negating it. The present work is meant to raise two related questions: first, whether Hegel's attribution of spiritual roles according to the natural genders of the family members is coherent with the most fundamental claims and concepts of his system, such as the relation between the notions of nature and spirit; second, whether Hegel's philosophy can achieve its most fundamental purpose, which is to realize the idea of freedom in the instance of family.

KEYWORDS: Family; Gender; Nature; Spirit; Reason.

\section{Introdução}

A Filosofia do Direito é, segundo Hegel, a exposição da ideia de direito - isto é, seu conceito e sua efetivação (cf. HEGEL, Filosofia do Direito, $\S 1)^{2}$ : a exposição da vontade livre "de modo que a liberdade constitui sua substância e sua determinação e que o sistema do direito é o reino da liberdade efetivada" (HEGEL, FD, §4). Para Hegel, a liberdade se efetiva também - e principalmente - na esfera da eticidade: é nas instituições éticas que o Bem da moralidade ganha conteúdo concreto, a saber, na família, na sociedade civil-burguesa e no Estado. Nesse sentido, a noção de família aparece como uma das raízes éticas do Estado $^{3}$, sendo o primeiro momento dessa eticidade - o primeiro momento, portanto, das instituições éticas que efetivam a ideia de liberdade. Dessa forma, a família é a instituição ética mais imediata de efetivação da liberdade. Hegel, então, pretende expor a noção de família na Filosofia do Direito de acordo com o seu conceito, isto é, de acordo com a vontade e seu ser aí "como totalidade da ideia" [de liberdade] que "a tem por fundamento e conteúdo" (HEGEL, FD, §143). Para isso, Hegel distribui papéis dentro da família para os indivíduos de acordo com o sexo de cada $u^{4}$ e, por isso, de acordo com a sua natureza, uma vez que a família é o espírito ético mais imediato ou natural (cf. HEGEL, FD, §157). No entanto, a nosso ver, ao determinar esses papéis na família associando seu sexo natural a papéis espirituais, Hegel os fixa, permanecendo no âmbito do entendimento, quando o que ele pretende fazer é determinar a noção de família do ponto de vista da razão, isto é, dando espaço para o movimento dialético, ainda que a família seja a instituição mais imediata - e natural, como Hegel mesmo assere - e ainda que essa discussão acerca das instituições faça parte especificamente do

\footnotetext{
${ }^{2}$ Filosofia do Direito doravante referida como FD.

3 "Depois da família, a corporação constitui a segunda raiz ética do Estado, a qual está fundada na sociedade civil-burguesa. A primeira contém os momentos da particularidade subjetiva e da universalidade objetiva numa unidade substancial; mas a segunda une, de modo interior, esses momentos" (HEGEL, FD, 255 - grifos do autor).

${ }^{4}$ Por exemplo, no $\$ 171$, quando Hegel diz que o homem é o chefe de família, como veremos mais adiante.
} 
espírito objetivo e, portanto, finito ${ }^{5}$, ou seja, ainda determinados por certas limitações relativas a eles, como veremos mais adiante. $\mathrm{O}$ objetivo deste trabalho, então, é determinar essas colocações hegelianas acerca dos papéis dos sexos na Filosofia do Direito e, a partir de teses fundamentais de seu próprio sistema, questionar a sua coerência interna, ainda que Hegel seja "filho do seu tempo" e esteja, de certo modo, determinado a uma visão de mundo específica. Para tanto, vamos retomar a crítica hegeliana ao entendimento e à razão, determinando o conceito de dialética; rever a relação entre natureza e espírito e analisar os papéis do homem e da mulher na família segundo Hegel.

\title{
Entendimento e Razão
}

Para Hegel, é necessário determinar adequadamente as tarefas do entendimento e da razão, para evitar, em filosofia, o erro no qual o idealismo transcendental de Kant teria caído: o de, ao se propor a fazer uma crítica da razão pura e determinar o que podemos conhecer a priori, acabar fazendo uma crítica do entendimento e determinar apenas o lado subjetivo do conhecimento, isto é, de permanecer em opiniões e não chegar ao conhecimento mesmo. Segundo Hegel, Kant teria cometido esse erro ao ser impreciso em suas distinções e, com isso, confundir as tarefas do entendimento com as da razão:

\begin{abstract}
é preciso compreender com isso o entendimento que abstrai e, assim, separa, persistindo em suas separações. Voltado contra a razão, ele se comporta como entendimento humano comum e faz valer sua opinião que a verdade repousa sobre a realidade sensível, que os pensamentos são apenas pensamentos, no sentido de que primeiramente a percepção sensível lhes dá conteúdo e realidade, que a razão, ao permanecer em si e para si, apenas produz quimeras. Nessa renúncia da razão a si mesma perde-se o conceito de verdade; a razão fica restrita a reconhecer somente a verdade subjetiva, apenas o fenômeno, apenas aquilo que não corresponde à natureza da questão mesma; o saber recaiu ao nível da opinião (HEGEL, Ciência da Lógica, p. 24 - grifos do autor $)^{6}$.
\end{abstract}

O entendimento, para Kant, estaria destinado a dar forma ao conteúdo da experiência sensível sem, contudo, chegar a conhecer a coisa em si mesma, uma vez que nós só teríamos acesso ao modo como as coisas aparecem para nós - às coisas determinadas segundo essas formas - e não ao modo como são nelas mesmas. Já a razão se ocuparia de, por um lado -

5 “O espírito subjetivo e o espírito objetivo são ainda finitos”. cf. HEGEL, Enciclopédia das Ciências Filosóficas, \$386ª . Enciclopédia das Ciências Filosóficas doravante referida como ECF.

${ }^{6}$ Ciência da Lógica doravante referida como CL. 
um lado positivo - determinar os princípios dessas formas, isto é, as regras das regras do entendimento: procura tratar das condições de possibilidade dos objetos empíricos serem conhecidos, ou seja, "dos elementos do conhecimento puro do entendimento e os princípios, sem os quais nenhum objeto pode, em absoluto, ser pensado" (KANT, Crítica da Razão Pura, A62/B87) ${ }^{7}$. Por outro lado, a razão também teria um aspecto negativo, determinando os limites do conhecimento humano ao determinar que os objetos que não podem ser submetidos à sensibilidade e às categorias do entendimento não podem ser por nós conhecidos, uma vez que só teríamos conhecimento acerca das coisas tais como aparecem para nós sob essas categorias. Dessa forma, estariam excluídos do nosso conhecimento unicamente através da razão pura objetos metafísicos, como Deus ou a liberdade. Kant chama o lado positivo da razão de Analítica Transcendental - ou "lógica da verdade" - e o lado negativo, de Dialética Transcendental ou "lógica da aparência" (Cf. KANT, CRP, A62/B87 e A293/B349)".

Para Hegel, Kant já minaria seu projeto desde a sua raiz: o problema mais fundamental estaria em separar essencialmente os objetos como são dos que podemos conhecer - ou seja, do modo como nos aparecem insistindo em um dualismo essencial. Hegel tenta dissolver esse dualismo, determinando que o modo como os objetos aparecem para nós são o modo como eles são neles mesmos, pois nosso modo de acesso à realidade é o mesmo do modo através do qual a realidade é nela mesma. Em outras palavras, Hegel aposta na unidade essencial do ser e do pensar, que Kant tomaria como coisas separadas desde o seu fundamento. A noção de lógica, para Hegel, já é, portanto, diferente em sua raiz: a lógica é a determinação das categorias do pensamento na mesma medida em que é a determinação da realidade. No entanto, essa realidade, para Hegel, não é apenas a realidade meramente empírica, na qual as coisas são uma multiplicidade de objetos que são por nós experimentados, mas sim um outro aspecto da realidade: uma realidade conceitual, a qual é a tarefa da filosofia investigar?

\footnotetext{
${ }^{7}$ Crítica da Razão Pura doravante referida como CRP.

${ }^{8}$ Kant determina que a dialética em geral é uma lógica da aparência, mas que nem por isso é enganadora. No entanto, a dialética transcendental deve ocupar-se de "descobrir a aparência de juízos transcendentes evitando ao mesmo tempo que essa aparência nos engane; mas nunca alcançará que essa aparência desapareça (como a aparência lógica) e deixe de ser aparência. Pois trata-se de uma ilusão natural e inevitável [...] enquanto a dialética lógica [...] apenas tem de descobrir um erro na aplicação dos princípios, ou uma aparência artificial na sua imitação" (KANT, CRP, A297-8/B354 - grifos do autor). Assim, a dialética transcendental é a lógica da aparência porque determina esses erros de aplicação dos princípios da analítica, determinando os limites do conhecimento através da razão pura.

9 Essa passagem de uma investigação acerca da realidade empírica para a realidade conceitual é o ganho da Fenomenologia do Espírito, mais precisamente, é o ganho da figura do saber absoluto. Não pretendemos nos deter nesse ponto, mas apenas mantemos presente aqui que, durante o percurso da consciência, ela se depara com diferentes objetos e diferentes modos de acesso a eles, determinando-os de acordo com isso na relação com eles. Então, a consciência compreende que aquela multiplicidade de objetos são, na
} 
Então, a filosofia investiga a realidade, segundo Hegel, justamente porque investiga as categorias do pensamento. Para isso, é preciso determinar o método pelo qual essas categorias são por nós descobertas. Segundo Hegel, esse método é o dialético, ou ainda, dialético-especulativo, pois é ele que mantém o movimento interno da realidade nela mesma enquanto nós a conhecemos, sem transformar tudo em peças de um quebracabeça estático ou peças de uma engrenagem mecânica. Isso porque, para Hegel, esse método explora o entendimento e a razão de maneira adequada.

O entendimento, ou o lado abstrato da lógica, é o momento da determinidade fixa, "na diferenciação dela em relação a outra determinidade" na relação de opostos enquanto opostos, enquanto diferentes em relação um ao outro (HEGEL, ECF, §80). É o momento de precisão, que evita o vago e o indeterminado (cf. HEGEL, ECF, §80A), para que se possa prosseguir numa investigação a fim de determinar seu recorte e nela não se perder.

A razão, por sua vez, tem dois aspectos: o negativo, ou dialético, e o positivo, ou especulativo.

O momento dialético, segundo Hegel, é "o próprio suprassumir-se (aufheben) de tais determinações finitas e seu ultrapassar para suas opostas" (HEGEL, ECF, §81). O momento negativo é, portanto, a própria negação, a negação das determinações fixas do entendimento. No entanto, não é uma negação que meramente anula essas oposições e determinações, como seria a atitude de um cético que põe abaixo todas as determinações ficando apenas na negatividade do momento, mas uma negação que ultrapassa a cisão das determinações fixas e opostas, negando a relação de oposição, não as suas determinações.

\footnotetext{
Em sua determinidade peculiar, a dialética é antes a natureza própria e verdadeira das determinações-do-entendimento - das coisas e do finito em geral. A reflexão é, antes de tudo, o ultrapassar sobre a determinidade isolada, e um relacionar dessa última pelo qual ela é posta em relação - embora sendo mantida em seu valor isolado. [...] é esse ultrapassar imanente, em que a unilateralidade, a limitação das determinações do entendimento é exposta como ela é, isto é, como sua negação" (HEGEL, ECF, $\S 81$ - grifos do autor).
}

É importante frisar que Hegel faz uma distinção entre os termos determinidade (Bestimmtheit) e determinação (Bestimmung). Em linhas gerais, uma determinação só é possível através de um movimento reflexivo, isto é, a coisa se põe como oposta a si mesma, mas apenas aparentemente e,

verdade, um único objeto, a realidade - em seu nível conceitual. O conceito une os objetos múltiplos em um objeto uno, a realidade, e esse é, então, o verdadeiro objeto da investigação filosófica. Para uma ampliação dessa tese, ver Baillie, The Origin and Significance of Hegel's Logic: a general introduction to Hegel's system, em especial o capítulo VII (sobre a passagem da Fenomenologia à Ciência da Lógica). 
a partir dessa aparente oposição, ela se dá determinações. Já a determinidade é uma relação consigo mesma e com um outro, e, mediada por esse outro não mais uma alteridade aparente aqui -, ela se determina. Por exemplo, o ser (Sein) do início da Lógica confere a si uma determinidade somente quando se coloca em relação com o nada (Nichts), quando passa para ele, pois como é esse primeiro ser, puro e abstrato, ainda não tem, em si mesmo, nenhuma determinação - em um primeiro momento, em relação apenas consigo mesmo, o ser é indeterminado. $\mathrm{O}$ nada surge de dentro do ser - o ser é nada, nesse sentido, pois não tem determinação alguma. Mas, a partir dessa relação com o nada, com algo outro que é negatividade, o ser se dá a si mesmo determinações - ele se determina numa categoria mais complexa que expõe o seu movimento próprio, a saber, o vir a ser ou devir (Werden).

Então, nos trechos acima citados, Hegel apresenta o entendimento como fixando, primeiramente, determinidades - ou seja, fixando qualidades das coisas a partir de si mesmos mas em relação de negatividade com outras coisas; por isso, o entendimento fixa oposições e é nessa relação com algo outro que as coisas conseguem se determinar a si mesmas, pois, em relação a elas mesmas, são indeterminadas. Em um segundo momento, ele coloca a dialética como um ultrapassar dessas determinidades, um ultrapassar da indeterminação em si mesmo da coisa e do ganho de determinação apenas na relação com outro: não é meramente as determinações do entendimento que são problemáticas (não necessariamente "erradas", mas talvez "inadequadas"), mas o próprio colocar-se na relação de oposição para haver determinações, a determinidade, que é problemática. É isso que a dialética faz aparecer: a negação da relação que o entendimento estabelece, não apenas as suas determinações. Assim, a dialética é, para Hegel, o que movimenta o sistema e que dá fôlego à investigação científica em geral, mais especificamente à filosófica, pois provoca uma desconstrução da fixidez da oposição, sem necessariamente desconstruir as determinações as quais o entendimento produziu, apenas proporcionando a possibilidade de poder realoca-las de um modo diferente - o que acontece no próximo movimento da razão. A dialética, portanto, desconstrói a unilateralidade e sua limitação, permitindo que se possa, a partir daí, elevar o conhecimento a níveis cada vez mais profundos e complexos.

Por fim, o movimento especulativo é o que constrói algo mais complexo a partir do resultado dialético. A razão dialética rompe o isolamento das oposições, mas mantém o conteúdo das determinações; a especulativa une essas determinações em um todo mais complexo que o anterior, sendo assim uma "unidade de determinações diferentes" (HEGEL, ECF, §82 - grifos do autor). A coisa pode se determinar não apenas em oposição a algo outro, mas a partir de si mesma, em um movimento de reflexão, autônomo. A especulação, no idealismo absoluto, torna-se um pensar racional, isto é, é o pensar de determinações diferentes 
do ponto de vista de uma unidade, ultrapassando as imediatas oposições e relacionando-as de uma nova maneira, de uma maneira mais concreta.

Assim, a razão especulativa ultrapassa também a abstração do entendimento e vem a ser pensamento concreto: as abstrações do pensamento, isto é, suas considerações das coisas de maneira fixa, isoladas umas das outras e em oposição umas às outras, para a investigação científica - e filosófica, portanto, para Hegel - é absolutamente necessária, pois, como vimos acima, ela evita o vago e o indeterminado, realizando um recorte sobre o qual trabalhar. No entanto, embora entender seja uma condição do conhecimento para Hegel, permanecer nessas considerações fixas é permanecer em abstrações; é necessário, para construir um pensamento concreto, questionar e reconsiderar, sempre e cada vez mais, essas abstrações. No entanto, não é meramente uma anulação das determinações do entendimento, mas sua reconsideração: não é permanecer em um abstrato que anula e esquece seu contexto, mas, a partir dessa abstração, engendrar uma nova consideração, uma nova determinidade e, consequentemente, novas determinações; pensar concretamente é, para Hegel, considerar algo na sua totalidade, "conectado indissoluvelmente com outras coisas: uma unidade de elementos, um ponto de encontro de opostos" (WALLACE, 1984, p. 304) $)^{10}$.

Em outras palavras, esse movimento todo é a própria suprassunção: na especulação está contido o entendimento, embora seja negado, dialeticamente, seu modo mais imediato de colocar as coisas, a saber, como fixas e opostas, e seu conteúdo é conservado e elevado em uma unidade mais complexa e profunda. Esse é o movimento próprio da filosofia: "a filosofia em geral nada tem a ver, absolutamente, com simples abstrações ou pensamentos formais, mas somente com pensamentos concretos" (HEGEL, ECF, §82), pois a filosofia não deve permanecer no momento do entendimento, mas sim duvidar de oposições meramente dadas e fixadas, questionando-as e construindo, com isso, novos pontos de vista que, eventualmente, assumirão oposições com alguns outros pontos de vista, que devem ser novamente questionados dialeticamente, permitindo que o movimento interno do processo do conhecimento apareça e cumpra seu papel, a saber, o de permitir chegar à verdade.

Com isso presente, cabe questionar as determinações dos papéis de gênero na noção de família da Filosofia do Direito, pois, como dito anteriormente, a nosso ver, Hegel, ao determinar certos papéis na eticidade de acordo com o sexo das autoconsciências, permanece no âmbito do entendimento, ou seja, permanece em oposições fixas, não permitindo que haja movimento com relação a essas relações. No entanto, antes de chegarmos a isso, vamos retomar como Hegel compreende a relação entre

10 Tradução nossa. No original: "connected indissolubly with others: a unity of elements, a meeting-point of opposities". 
indivíduos de diferentes sexos na natureza e o que ele compreende como espírito, e, assim, como ele pretende que se supere a oposição imediata entre natureza e espírito, para, finalmente, questionarmos sua distribuição de papéis de acordo com os sexos na família da Filosofia do Direito.

\section{Natureza e Espírito}

Natureza, para Hegel, é a ideia como ser outro (cf. HEGEL, ECF, §247), isto é, a natureza tem como determinação sua a exterioridade, negação ou imediatez do todo efetivo que encerra a dimensão lógica. A ideia, grosso modo, é a totalidade lógica efetiva, isto é, é uma determinação do conceito - do objeto da lógica como um todo - complexa e completa, de modo que contém nela suprassumidas todas as determinações lógicas anteriores, mas agora o movimento "não é mais ultrapassar nem aparecer em Outro, mas é desenvolvimento" (HEGEL, ECF, §161 - grifo do autor), ou seja, é o desenvolvimento do que já está nele mesmo, do que ele já é, no conceito. "Na natureza", por exemplo, como diz Hegel, "é a vida orgânica que corresponde ao grau do conceito" (HEGEL, ECF, §161A), isto é, é o desenvolvimento do que está, por exemplo, na semente, que é o que a planta é. A natureza, portanto, é ser outro da ideia não porque está fora dela, mas porque é o modo da ideia se manifestar: é o modo mais imediato. A imediatez é a determinação da ideia na natureza; a natureza é manifestação imediata da ideia.

A ideia não é algo imediato nela mesma, mas contém em si a imediatez. Dessa forma, a ideia não é natureza, mas contém as determinações da natureza em si. A natureza, assim, manifesta-se de maneira exterior à ideia, pois é só um aspecto dela, o imediato - e negativo, porque a imediatez "consiste em que o diferente subsiste abstratamente por si” (HEGEL, ECF, §248A). A natureza subsiste sem a ideia - é exterior a ela, empiricamente falando - mas apenas de modo abstrato, isto é, desconsiderando as relações mais complexas que a própria realidade se dá (o que foi investigado ao longo da Ciência da Lógica). A natureza existe no sentido mais amplo do termo - fora de nós e é, dessa forma, exterior à ideia, mas, em um sentido mais elevado de realidade - o conceitual - a natureza existe na ideia porque é um aspecto dela, é um modo de manifestação da ideia, essa que é, para Hegel, a verdade no seu sentido mais profundo: "pois a verdade é que a objetividade corresponda ao conceito, não que as coisas exteriores correspondam a minhas representações" (HEGEL, ECF, §213). Em outras palavras, os objetos são verdadeiros "quando são o que devem ser, isto é, quando sua realidade corresponde ao seu conceito" (HEGEL, ECF, §213A - grifo do autor). Pensar sobre a natureza - que é um aspecto, portanto, da realidade - ou seja, investigá-la e fazer aparecer suas categorias e, assim, relacioná-la ao conceito é, portanto, torná-la mais concreta e reconciliá-la com o seu outro, 
a lógica. Essa reconciliação da natureza com a lógica se dá no espírito e, por isso, isto é, por ser totalidade efetiva, o espírito é a verdade da natureza.

É no espírito que são suprassumidas (negadas, porém conservadas e elevadas a outro nível mais complexo) as diferenças entre natureza e lógica, isto é, é somente, segundo Hegel, através do pensar filosófico - que é capaz de reunir aparentes multiplicidades em uma unidade mais complexa e fundamental, porque o faz conceitualmente - que se pode reconhecer "que a natureza não é simplesmente idealizada por nós; que o seu 'fora-um-dooutro' não é algo totalmente insuperável para ela mesma, para o seu conceito" (HEGEL, ECF, §381 - grifo nosso.).

O espírito é, assim, a totalização dos momentos anteriores bem como sua unificação, não meramente negando suas determinações, mas conservando-as, dando a elas um novo grau de complexidade e tornando-as concretas. Isso só é possível através do pensamento filosófico, ou seja, através do ser humano, que é o único que consegue dar esse passo, pois é espírito pensante:

só o homem se eleva, por cima da singularidade da sensação, à universalidade do pensamento, ao saber de si mesmo, ao compreender de sua subjetividade, de seu eu; [...] e por isso e, na verdade, só por isso - é essencialmente diferente da natureza. $\mathrm{O}$ que pertence à natureza, como tal, fica atrás do espírito; ele tem, certamente, em si mesmo o conteúdo total da natureza; porém as determinações naturais são, no espírito, de uma maneira totalmente outra do que são na natureza externa (HEGEL, ECF, §381A).

A natureza não conhece a si mesmo, não se compreende, a não ser pelo ser humano que a pensa e a relaciona, e faz suas categorias emergirem de dentro dela. Por isto, o ser humano é diferente da natureza: porque é capaz de se conhecer a si mesmo e, com isso, superar as determinações naturais limitadas e fixas.

Eis aqui nosso ponto crucial: se o ser humano é capaz de superar as determinações da natureza justamente porque pode pensa-las e, assim, conhecer-se a si mesmo, sendo, com isso, algo diferente da natureza, embora as mantenha conservadas nessa superação, suprassumindo-as, como as determinações a partir dos sexos naturais na família da eticidade hegeliana podem se manter fixas segundo o conceito de família? Com isso em mente, vejamos mais de perto como Hegel considera a relação das diferenças de sexo de um mesmo gênero ${ }^{11}$ na natureza.

${ }^{11}$ É importante ressaltar que Hegel utiliza "gênero" no sentido biológico, na Filosofia da Natureza, como um conjunto de espécies com mais ou menos as mesmas características. Por isso, optamos, neste trabalho, em não nos referirmos à distinção entre sexos como distinção entre gêneros, como algumas discussões em diversas áreas fazem hoje, justamente para manter as referências hegelianas mais claras: Hegel utiliza 'gênero' para se referir a esse conjunto entre indivíduos com mais ou menos as mesmas características, como o 
A relação entre diferença e identidade, já exposta na Ciência da Lógica $^{12}$, reaparece aqui referindo-se ao aspecto natural da distinção entre sexos dentro de seu gênero. O gênero, na Filosofia da Natureza, é o que unifica indivíduos com mais ou menos as mesmas características - por exemplo, o ser humano (gênero Homo) - é determinado numa relação: "a ideia, como se relacionando ao outro, que é ele próprio indivíduo vivente, e por aí no outro relacionando-se a si própria", isto é, o processo "mais alto, a saber, o da singularidade e universalidade do indivíduo diante de si como gênero, com o qual ele em si é idêntico" (HEGEL, ECF, §352 e §352A). O gênero explicita, assim, a relação de identidade entre indivíduos diferentes na medida em que eles se relacionam pelo que tem em comum. Em cada gênero, no entanto, há distinções entre espécies de acordo com diferenças mais pontuais - no humano (Homo), por exemplo, temos a habilis (já extinta) e a sapiens (a nossa), diferenciadas pelo tamanho de seu crânio. No entanto,

esta primeira diferenciação do gênero em espécies [...] é apenas uma atitude negativa e hostil perante os outros. Mas o gênero é do mesmo modo relação essencialmente afirmativa da singularidade sobre si nele, de modo que ele, enquanto é, exclusivamente um indivíduo diante de outro individuo, se continua neste outro e a si mesmo se sente neste outro. Esta relação é processo e começa com a necessidade, enquanto o indivíduo [...] está numa unidade; tem assim o sentimento desta deficiência. $\mathrm{O}$ gênero nele é portanto, como tensão conta a inadequação de sua realidade singular, o impulso de conseguir no outro do seu gênero sua auto-sensação, pela união com ele integrar-se e por meio desta mediação encadear

conceito biológico de 'gênero', e não como uma distinção entre sexos dentro desse mesmo conjunto. Portanto, toda referência hegeliana a gênero tem esse significado biológico; às diferenças naturais entre homem e mulher apontaremos apenas como seus respectivos sexos.

${ }^{12} \mathrm{O}$ segundo capítulo da Doutrina da Essência é dedicado às determinações da reflexão ou às essencialidades, dentre as quais a identidade e a diferença. De maneira bastante rasa, mas para tornar esse ponto presente aqui: nessa relação, a identidade, através do movimento de reflexão, coloca-se como oposta à diferença; no entanto, essa oposição é aparente: da identidade entre identidade e diferença surge a contradição, motor da filosofia hegeliana. A contradição é a unidade da identidade e da diferença, mantendo ambas as determinações, mas elevando-as a novas considerações, a saber, que só há determinação da identidade a partir da diferença, e que só há determinação da diferença a partir da identidade. A contradição, para Hegel, é a unidade do positivo e do negativo, da identidade e da diferença, enquanto cada uma delas é idêntica a si mesma e em relação à outra, não em mera oposição, pois, segundo Hegel, o conceito de contradição tradicional supõe que as coisas são opostas, e, aqui, Hegel apresenta uma unidade mais fundamental que contém nela as supostas oposições, ou, melhor dito, uma unidade mais fundamental que contém nela a multiplicidade das diferenças, sem anulá-las, mas identificando-as umas com as outras. É na relação de uma com a outra, suprassumindo a oposição de uma a outra, que é possível chagar a uma unidade mais profunda e concreta: o fundamento. 
consigo e trazer a existência o gênero - é a cópula (HEGEL, $\mathrm{ECF}, \S 369$ - grifos do autor).

A cópula, para Hegel, é um momento positivo dentro do gênero, pois equilibra a tensão das diferenças dos sexos no outro, numa unidade, pois gera algo igual a si em uma nova unidade:

a separação de ambos os sexos é tal, que nela estão as totalidades extremas da auto-sensação; o impulso do animal é a produção de si como de uma auto-sensação, como totalidade [...] A ideia da natureza está aqui realmente no par de um macho e fêmea; sua identidade, como seu ser-para-si, que até agora estavam somente para nós em nossa reflexão, são agora sentidos na infinita reflexão dos dois sexos em si por eles mesmos" (HEGEL, ECF, §369A).

A relação sexual expõe, segundo Hegel, a diferença natural dos sexos, mesmo que façam parte de uma mesma unidade, de um mesmo gênero, pois permite que eles sintam sua própria identidade: "aqui, cada um dos sexos não sente no outro uma exterioridade estranha, mas [sente] a si mesmo, ou o gênero comum aos dois (HEGEL, ECF, §381A). No entanto, ainda que eles sintam essa identidade, não são ainda uma unidade, uma universalidade concreta: "o indivíduo é só um dos dois e não existe como unidade, mas somente como singularidade” (HEGEL, ECF, §369A - grifo nosso). $\mathrm{O}$ aspecto natural, porque natural - e, portanto, como ser outro da ideia - é ainda abstração, que não permite a totalização que o espírito vai operar. "Assim, a natureza, mesmo no píncaro mais alto de sua elevação sobre a finitude, recai sempre de novo na finitude e apresenta dessa maneira um movimento circular constante" (HEGEL, ECF, 381A). A diferença dos sexos, ou seja, a diferença natural entre homem e mulher não pode ser resolvida pela natureza, mas pode ser resolvida pelo espírito, na medida em que ele é capaz de totalizar essas determinações, sem, no entanto, anulá-las.

Hegel apresenta o espírito ${ }^{13}$ como dividido em três partes: o espírito subjetivo, o espírito objetivo e o espírito absoluto. Ao primeiro, cabe questões antropológicas, fenomenológicas e psicológicas; ao segundo, questões acerca do direito, da moralidade e da eticidade e ao terceiro, questões acerca da arte, da religião e da filosofia. Como apontamos mais acima, os dois primeiros momentos do espírito são ainda finitos, ou seja, estão ainda determinados por certas limitações relativas a eles:

\footnotetext{
${ }^{13}$ No terceiro tomo da Enciclopédia das Ciências Filosóficas, A Filosofia do Espírito. Tomamos a Enciclopédia como base da nossa interpretação acerca do espírito aqui, embora a noção apareça em diversos outros escritos, como na Fenomenologia do Espírito, por oferecer em uma perspectiva de unidade o sistema do idealismo transcendental e, por isso, oferecer uma noção mais concisa de espírito, além de contrapor a noção à de natureza, já que é a parte imediatamente seguinte a ela.
} 
finitude tem aqui a significação da incongruência do conceito e da realidade com a determinação de que ela é o aparecer no seu interior. É um aparecer que em si o espírito se impõe como um limite, a fim de que para si, pelo suprassumir desse limite, tenha e saiba a liberdade como sua essência, isto é, que seja pura e simplesmente manifestado" (HEGEL, ECF, \$386 grifos do autor).

Ainda que a natureza esteja contida no espírito, isto é, ainda que as determinações naturais sejam suprassumidas no espírito, "o espírito, enquanto espírito, não é finito; ele tem a finitude em si mesmo, mas somente como uma finitude a suprassumir e suprassumida" (HEGEL, ECF, $\$ 386 \mathrm{~A}$ - grifos do autor). A finitude desses dois primeiros momentos do espírito, o subjetivo e o objetivo, é, pois, diferente da finitude da natureza

justamente porque seu limite não é presente para elas mesmas, mas só para nós que as comparamos umas com as outras. Fazemos de nós mesmos algo finito pelo fato de acolhermos um Outro em nossa consciência. Mas justamente, enquanto sabemos desse Outro, estamos além desse limite (HEGEL, ECF, §386A - grifos nossos.).

O que permitirá ultrapassar de vez esse limite será o espírito absoluto, através da arte, da religião e da filosofia.

Assim, ainda que o espírito objetivo, aspecto que nos interessa mais diretamente neste trabalho, seja finito, e ainda que conserve as determinações naturais - e, portanto, as diferenças de sexo naturais podemos questionar se ele deveria permanecer atrelado a essas determinações, ou ainda, se ele deveria basear papéis espirituais nessas determinações, uma vez que, embora as contenha, deve, como vimos, suprassumí-las e ir além desses limites. Passemos às considerações mais pontuais que Hegel faz na Filosofia do Direito acerca desses papéis, para retomarmos nossa crítica sobre os diferentes aspectos que apresentamos aqui.

\section{Homem e mulher na noção de família da Filosofia do Direito}

A família, como dissemos acima, é o primeiro momento da eticidade. A eticidade (Sittlichkeit), no idealismo absoluto, surge da dissolução da moralidade e do seu engendramento nos costumes (Sitten) de um povo em um tempo histórico específico. Em outras palavras, a eticidade é a realização - ou melhor, a efetividade - do $\operatorname{Bem}^{14}$ (que, na moralidade, é

\footnotetext{
${ }^{14}$ Segundo Hegel, o Bem é "é a ideia enquanto unidade do conceito da vontade e da vontade particular" (HEGEL, FD, §129 - grifos do autor), isto é, é a efetivação do conceito de vontade através do sujeito em situações particulares. Na moralidade, as ações do sujeito são autodeterminadas por ele a partir do seu reconhecimento de algo como bom
} 
efetivado através de vontades subjetivas em situações particulares) nas instituições da eticidade, a saber, na família, na sociedade civil-burguesa e no Estado.

A família, então, é uma unidade mais imediata, é o momento do "espírito ético imediato ou natural" (HEGEL, FD, $\$ 157$ - grifo do autor.). Dessa forma, os indivíduos na família, segundo o conceito, para Hegel, precisam "ter a autoconsciência de sua individualidade nessa unidade enquanto essencialidade sendo em si e para si, a fim de ser nela não uma pessoa para si, porém como membro" (HEGEL, FD, §158 - grifos do autor). Em outras palavras, embora a família esteja ainda mais ligada à natureza do que as outras instituições, os indivíduos não se relacionam mais uns com os outros meramente como no aspecto natural, quer dizer, ainda que haja uma unidade natural com o outro - através do gênero - o indivíduo não é mais só um dos dois, uma singularidade. Na família - no espírito objetivo - o indivíduo preserva sua singularidade, mas como membro, como parte constituinte da unidade espiritual - essa singularidade é suprassumida na unidade, na figura do casamento:

o casamento, enquanto relação ética imediata, contém, primeiramente, o momento da vitalidade natural e, de fato, enquanto relação substancial, a vitalidade em sua totalidade, a saber, como efetividade do gênero e de seu processo [...]. Mas, em segundo lugar, a unidade dos sexos naturais, que é apenas interior ou sendo em si, e precisamente com isso apenas exterior em sua existência, é, na autoconsciência, transformada numa unidade espiritual, no amor autoconsciente" (HEGEL, FD, $§ 161$ - grifos do autor).

O casamento, para Hegel, conserva as determinações naturais, mas as suprassume, uma vez que os indivíduos não se casam, segundo o conceito $^{15}$, por impulso natural, mas pelo amor ético:

nele mesmo. No entanto, o Bem, por ser mediado pela vontade particular no momento da moralidade, ou seja, apenas pelo sujeito e por sua vontade, ele ainda é abstrato, ou ainda, é universalmente abstrato. Por ser abstrata, ainda que universal, a vontade tem aqui a ausência de determinação, e, por conseguinte, não tem conteúdo: é apenas formal. É necessário, então, para que o Bem seja concreto, para que ele seja efetivo, dar um conteúdo a essa forma. Esse conteúdo é dado na eticidade.

15 É evidente que, na realidade empírica, os indivíduos se casem por impulso natural, porque estão apaixonados, etc. Mas o ponto de Hegel é analisar o casamento do ponto de vista do conceito, ou seja, de um ponto de vista mais profundo e refletido, do ponto de vista em que as coisas "quando são o que devem ser, isto é, quando sua realidade corresponde ao seu conceito" (HEGEL, ECF, §213A - grifo do autor), como dissemos mais acima. Portanto, os indivíduos deveriam se casar não meramente por impulsos naturais (o que não significa que não possam haver impulsos naturais), mas porque o casamento é outra coisa além da natureza, é uma figura espiritual e, por isso, tem determinações segundo o conceito. Quais são essas determinações, no entanto, podem ser aqui questionadas. 
o ético do casamento consiste na consciência dessa unidade, enquanto fim substancial, com isso no amor, na confiança e na comunidade de toda a existência individual, - nessa disposição de espírito e efetividade, o impulso natural é rebaixado à modalidade de um momento natural, que é precisamente determinado a extinguir-se em sua satisfação, e o vínculo espiritual eleva-se em seu direito" (HEGEL, FD, §163 - grifo do autor).

O momento natural é suprassumido no espiritual, nesse caso, no ético: o que é essencial na relação espiritual é a unidade ética, não a natural. No entanto, para Hegel, essa suprassunção se dá de uma maneira específica: "a determinidade [Bestimmtheit] natural dos dois sexos recebe por sua racionalidade significação intelectual e ética” (HEGEL, FD, §165), isto é, cada um dos sexos têm determinidades na sua vida espiritual de acordo com seu aspecto natural:

O primeiro [aspecto], por isso, é o espiritual, enquanto se cinde na autonomia pessoal sendo para si e no saber e querer da universalidade livre, na autoconsciência do pensamento conceitualizante e no querer do fim último objetivo; - o outro [aspecto] é o espiritual que se mantém na unidade enquanto saber e querer do substancial, na forma de singularidade concreta e de sentimento; - aquele, em relação ao de fora, o potente e o ativo; esse, o passivo e subjetivo. Por isso, o homem tem sua vida substancial efetiva no Estado, na ciência e em coisas semelhantes, e também no trabalho e no combate com o mundo exterior e consigo mesmo, de modo que ele é somente a partir da cisão que conquista a unidade autônoma consigo, de maneira que possui a intuição tranquila e a eticidade subjetiva, que sente na família, na qual a mulher tem sua determinação [Bestimmung] substancial e nessa piedade tem sua disposição de espírito (HEGEL, FD, §166 - grifos do autor).

Chamamos atenção aqui, antes de mais nada, ao uso dos termos determinidade [Bestimmtheit] e determinação [Bestimmung] por Hegel nesses parágrafos cruciais. Como vimos mais acima, uma determinidade, grosso modo, é uma maneira de se determinar a partir de si e da sua relação com algo outro, numa relação de negação. Percebemos aqui que os sexos espirituais recebem a sua determinidade de acordo com os sexos naturais, ou seja, o espiritual recebe sua determinidade numa relação de oposição e negação com o natural - ou ainda, o natural passa para o espiritual, como o ser passa para o nada no início da Ciência da Lógica. Desse modo, na esfera da família - espiritual - há papéis de acordo com algo que define os seus membros a partir da relação com qualidades de outro nível, do nível natural, pois, de certo modo, já estavam lá (como o nada já estava no ser enquanto ele era indeterminado). Portanto, haverá diferenças entre os sexos que serão mantidas aqui, porque, apesar de haver um gênero que confere 
unidade aos membros da família, por ser uma instituição mais próxima à natureza, a natureza marca a sua diferença na família na diferença dos sexos de seus membros. Todavia, no parágrafo seguinte, o que Hegel nos oferece são as determinações (Bestimmungen) de cada um dos sexos espirituais, de acordo com as suas determinidades. Determinação é, como vimos anteriormente, para Hegel, uma relação interna, refletida, de uma determinidade: a determinidade, ao se opor, aparentemente (pois é uma unidade em seu fundamento), a si mesma, determina-se. Portanto, o que Hegel oferece no §166, se partirmos dessas considerações, é uma determinação imanente aos sexos naturais, que é transposta ao espiritual. Não é a determinidade do gênero - portanto, de algo que é uma unidade mais fundamental - que reflete em si mesma, e se opõe na diferença entre homem e mulher na unidade da família, mas é a determinidade natural enquanto diferença natural - a determinação de cada sexo - que é refletida: o homem tem determinações espirituais relativas ao seu próprio sexo natural e a mulher tem determinações espirituais relativas ao seu próprio sexo natural. Ou seja, Hegel determina papéis espirituais de acordo com o sexo natural; assim, Hegel determina o aspecto espiritual do homem como aquele que está voltado para si, isto é, para o pensamento conceitualizante e para o fim último objetivo, para o Estado e as coisas públicas, por assim dizer, porque seus órgãos sexuais são externos - "emergem para a oposição", tendo o homem um "cérebro producente e coração externo" (HEGEL, ECF, $\S 369 \mathrm{~A})$ - enquanto que a mulher, porque tem os órgãos sexuais internos, não emergindo para a oposição, mas permanecendo "em sua unidade não desenvolvida" (HEGEL, ECF, §369A), só pode ter seu aspecto espiritual voltado para a família, para o saber e querer das coisas privadas, por assim dizer, sob a forma de singularidade concreta (pois não é mais mera singularidade natural, mas espiritual) e sentimento, sendo piedosa ${ }^{16}$. Dessa maneira, Hegel parece legitimar os costumes do seu tempo a partir da relação entre o espiritual e o natural, comprometendo-se com a visão moderna dos papéis do homem e da mulher - e não meramente segue o senso comum da época, ainda que seja um filho de seu tempo. Mesmo que possamos defender a posição de Hegel, afirmando que ele é um homem de seu tempo, portanto, não pode pensar tão longe dos costumes de sua época, podemos, entretanto, questionar a validade de sua conclusão no conceito de família: podemos questionar se de suas premissas (de suas bases do sistema

\footnotetext{
${ }^{16} \mathrm{O}$ adendo (Zusatz) a esse parágrafo ainda exagera mais nos papéis da mulher, baseandose na sua capacidade intelectual limitada - "mulheres podem ser bem formadas, mas elas não são feitas para as ciências mais altas, para a filosofia e para a produção certa da arte, que demanda um universal" - além de comparar as mulheres com plantas - "a diferença entre homens e mulheres é a dos animais e das plantas" (HEGEL, Grundlinien der Philosophie des Rechts, p. 319). Todavia, é preciso lembrar que os adendos aos parágrafos da Filosofia do Direito são escritos por alunos de Hegel a partir de suas aulas. Ainda que Hegel pudesse ter dito tais palavras em sala de aula, não estamos livres de observações mais subjetivas de seus alunos aqui, portanto, neste trabalho, não consideramos os adendos.
} 
do idealismo absoluto) segue-se necessariamente sua conclusão, suas determinações acerca dos papéis do homem e da mulher. Vejamos, então, esse passo hegeliano.

Hegel retoma, neste momento, a tragédia da Antígona de Sófocles (Cf. HEGEL, FD, observação ao §166) ${ }^{17}$ como exemplo de como a piedade é uma característica da mulher, uma vez que é relacionado a ela a lei dos antigos deuses, uma "interioridade que ainda não alcançou sua realização perfeita" em oposição à lei do Estado, relacionada ao homem (a Creonte). Polínices, irmão de Antígona, disputava o trono de Tebas com o outro irmão, Etéocles. Polínices, que ataca Tebas pelo trono, é traído pelo irmão, que a defendia, e ambos matam-se um ao outro. Antígona, por ser irmã de Polínices, quer seguir a "lei divina", que garante ao morto honras fúnebres, mas Creonte, que defende a "lei do Estado", proíbe o enterro de Polínices, pois este estaria, ao atacar a cidade (polis), colocando-se acima dela, portanto, indo contra ela. Dessa forma, Antígona representaria essa individualização da feminilidade e da masculinidade, uma vez que a mulher se colocaria, para Hegel, como defensora da família, enquanto o homem, do Estado. No entanto, ainda que essa seja a linha principal do texto, poderia se questionar se de fato Antígona estaria meramente defendendo a lei da família frente à lei do Estado, ou se estaria também questionando, ao confrontar Creonte, o dualismo dessas leis, que, da maneira como a peça coloca, expressa uma contradição imanente e aparentemente indissolúvel na constituição da polis tebana ${ }^{18}$. Talvez Antígona não esteja se fixando em oposições tanto quanto Creonte e que ela, com sua atitude de questionar, esteja dando um passo dialético frente essas oposições. Além disso, a interpretação de Rosenfield ${ }^{19}$ defende que o que está realmente em jogo na atitude de Antígona é sua linhagem - ela é descendente dos fundadores de Tebas, enquanto Creonte é descendente da linhagem de regentes, conselheiros reais e auxiliares do trono. Dessa forma, Antígona estaria defendendo algo ainda mais fundamental do que a lei divina ou indo contra a lei do Estado: estaria defendendo um direito, a partir dos quais as leis

\footnotetext{
${ }^{17}$ Não vamos entrar aqui em uma interpretação extensa e mais dedicada à Antígona, mas gostaríamos de manter presente ao menos uma outra interpretação possível, dada no texto acima, que vai de encontro à posição hegeliana aqui.

18 Embora não nos detenhamos nesse ponto aqui, é importante frisar que, na Fenomenologia (ver FE, §446-476), Hegel traz a peça Antígona como mostrando justamente o dualismo das leis (por exemplo, da lei divina e da lei do estado, da lei da mulher e da lei do homem, da lei natural e da lei espiritual) e como isso contribuiu para a decadência da polis grega, pois é desse impasse dualista que a figura da eticidade grega dá lugar à figura do direito romano. No entanto, Hegel parece, aqui, dar ênfase justamente ao dualismo, mantendo as diferenças presentes e transpondo-as para o conceito de família - o que, a nosso ver, é, ao menos, estranho, uma vez que Antígona se refere ao modelo de eticidade de uma época específica, e, portanto, já superada, segundo a própria Fenomenologia.

${ }^{19}$ Ver a Introdução da edição da Antígona de Sófocles de 2006, de Kathrin Rosenfield, que se baseia nas traduções e notas de Hölderlin, poeta próximo de Hegel.
} 
deveriam surgir. Com isso, Antígona - a mulher - estaria também preocupada com o público, não apenas com o privado, porque a família dela, nesse caso, é a família que governa o estado. Todavia, uma dedicação maior a essa interpretação seria necessária para desenvolver mais o tema, o que não é nosso objetivo fazer aqui.

Nos parágrafos seguintes do conceito de família, Hegel explicita os aspectos acima apontados, determinando papéis específicos de acordo com eles: o homem é o chefe de família e a representa enquanto pessoa jurídica frente a outras famílias (já em uma relação pública, portanto), administrando o patrimônio familiar, cuidando para que todos os membros da família participem desse patrimônio, não carecendo eles de nada (cf. HEGEL, FD, §171) e na dissolução da família, os filhos formam uma nova família, sendo chefes, e as filhas, esposas (cf. HEGEL, FD, §177). A relação hegeliana entre público e privado com o externo e o interno dos órgãos sexuais é clara, mas, a nosso ver, não é válida.

Ainda que Hegel argumente que a família não é uma suprassunção completa da natureza, justamente porque o espírito objetivo, do qual a família é momento, é ainda finito e porque a família ainda está intimamente ligada à natureza, pois é o espírito ético imediato - ou natural -, Hegel não poderia, se quisesse ser mais coerente com a sua filosofia: a) fixar essa determinações espirituais, determinando que, por exemplo, o homem é o chefe da família e a mulher é apenas a esposa, pois, como vimos anteriormente, isso é permanecer no nível do entendimento e não no da razão, e Hegel pretende que sua apresentação da noção de família seja de acordo com o conceito - acessível apenas dialético-especulativamente; b) derivar tais determinações espirituais da constituição natural porque elas não dependem apenas da natureza, mas também (e necessariamente, segundo o próprio Hegel) dos costumes (Sitten $)^{20}$ nos quais os indivíduos estão inseridos. Se a noção hegeliana de família pretende ser um modo de efetivação da ideia da liberdade, ela deve poder deixar espaço para que as determinações espirituais dos indivíduos possam mudar de acordo com as mudanças históricas e com seus respectivos costumes e, assim, seguir o movimento próprio do conceito: o movimento de desenvolvimento de si mesmo em si e para si. É preciso deixar em aberto, por exemplo, a possibilidade de as mulheres virem a ser chefes de família, de que elas possam se voltar às coisas públicas - o que tem acontecido muito frequentemente em nossa eticidade - porque isso é uma determinação que depende essencialmente dos costumes de uma época, não de determinações naturais. Ao fixar esses papéis na família de acordo com seus sexos naturais,

\footnotetext{
20 " $\mathrm{Na}$ identidade simples com a efetividade dos indivíduos, o ético aparece como modo de ação universal deles - como costume - o hábito deles como uma segunda natureza, que é posta no lugar da vontade primeira meramente natural, e são a alma, a significação e a efetividade que penetram seu ser-aí, o espírito vivo e presente enquanto mundo, cuja substância somente assim é como espírito" (HEGEL, FD, §151. - grifos do autor)
} 
não apenas permanecemos no entendimento (o que, para Hegel, é um problema grave dos que estão dispostos a fazer filosofia); não apenas confundimos determinações variáveis de acordo com o período histórico e seus costumes, como não deixamos o conceito mesmo se desenvolver, seguindo sua própria (e verdadeira, para Hegel) lógica.

A nosso ver, então, Hegel não parte, nessa transição da natureza para o espírito no momento da família, do ponto de vista mais fundamental, quer dizer, do ponto de vista da unidade. Hegel toma o dualismo, a diferença, o singular como o mais fundamental, e não a unidade, a identidade e o universal - mais uma vez, justamente o que ele critica com bastante afinco. Assim, o ponto de partida ideal para a determinação da família na filosofia hegeliana, se ele fosse aqui coerente com a própria filosofia, seria o gênero humano, uma unidade conceitual que reúne em si as diferenças dos sexos, conservando-as, como a unidade conceitual que Hegel chama de realidade reúne em si a multiplicidade de objetos empíricos. Apesar de Hegel chamar atenção para que, no conceito de família, os indivíduos são como membros (cf. HEGEL, FD, §158), e o casal renuncia "à sua personalidade natural e singular nessa unidade" (HEGEL, FD, §162 - grifos nossos), são as diferenças naturais que são determinantes para os papéis que os membros têm na família. Partir dessa unidade possibilitaria que houvesse determinações espirituais e éticas para ambos os sexos, mas que elas não fossem fixas - que elas pudessem ser atribuídas de acordo com os costumes, ou, indo mais longe, que elas pudessem ser intercaladas entre homem e mulher, pai e mãe (pois as determinações naturais não impedem que a mulher possa participar e ensinar as crianças sobre vida pública, e não impede que o homem possa ensinar os filhos e participar plenamente da vida familiar); partir da unidade possibilitaria que as determinações familiares pudessem ser desenvolvidas de acordo com o conceito, como Hegel pretendeu inicialmente.

\section{À Guisa de conclusão}

Nosso trabalho, em suma, pretendeu questionar as posições hegelianas com relação aos papéis do homem e da mulher na família da Filosofia do Direito, confrontando o argumento hegeliano com algumas premissas mais fundamentais de seu próprio sistema. O que é evidente, no entanto, é que para o conceito de família hegeliano não há espaço para a possibilidade de casamento homossexual: a família, para Hegel, tem necessariamente como pilar o casamento heterossexual, pois, para ele, a família se realiza, além da figura do casamento e da propriedade, na geração (além da educação) de filhos pelo casal, ligado diretamente à reprodução natural. A reprodução do gênero humano só é possível com elementos do aparelho reprodutor feminino e do masculino e os filhos são o resultado (cf. HEGEL, FD, §173), segundo o aspecto natural, dos pais. É na concepção, 
segundo Hegel, que as abstrações do feminino e do masculino tornam-se uma (cf. HEGEL, ECF, §369A); é assim que é possível, para ele, que a diferença e a identidade se relacionem. Essa seria, então, a explicitação do conceito de família; é importante frisar que as famílias, na realidade empírica, poderiam não realizar esse conceito plenamente por diferentes motivos - como, por exemplo, um casal que tem fillhos mas não são casados - faltaria a determinação do casamento, aqui. Ainda assim, um casal homossexual, ainda que adotasse filhos, de acordo com o conceito exposto por Hegel, propriamente família, pois a determinidade natural não tem como ser suprassumida pela espiritual. A nosso ver, esse conceito que Hegel apresenta, por permanecer em determinações fixas relativas ao seu tempo e, assim, não deixar espaço para a dialética suprassumir as determinações naturais através das espirituais, não dá conta de uma das teses de seu sistema, a saber, que o conceito de liberdade efetivamente se desenvolva no âmbito familiar em qualquer época.

\section{Referências bibliográficas:}

BAILLIE, James. B. The origin and significance of Hegel's logic: a general introduction to Hegel's system. Kitchener: Batoche Books, 1999.

HEGEL, Georg. W. F. Ciência da lógica: Excertos. São Paulo: Barcarolla, 2011 .

. Enciclopédia das ciências filosóficas em compêndio. São

Paulo: Loyola, 1995.

. Linhas fundamentais da filosofia do direito. São Leopoldo:

Editora Unisinos, Editora Unicap, Edições Loyola, 2010.

KANT, Immanuel. Crítica da razão pura. Lisboa: Fundação Calouste Gulbekian, 2010.

SÓFOCLES. Antígona. Rio de Janeiro: Topbooks, 2006.

WALLACE, William. The logic of Hegel: Prolegomena to the study of Hegel's philosophy and especially of his Logic. Oxford: Claredon Press, 1894. 